\title{
Vasopressin Generates a Persistent Voltage-dependent Sodium Current in a Mammalian Motoneuron
}

\author{
Mario Raggenbass, Michel Goumaz, Edoardo Sermasi, Eliane Tribollet, and Jean Jacques Dreifuss \\ Department of Physiology, University Medical Center, $\mathrm{CH}-1211$ Geneva, Switzerland
}

During the period of life that precedes weaning, the facial nucleus of the newborn rat is rich in ${ }^{3} \mathrm{H}$-vasopressin binding sites, and exogenous arginine vasopressin (AVP) can excite facial motoneurons by interacting with $V_{1}$ (vasopressor-type) receptors. We have investigated the mode of action of this peptide by carrying out single-electrode voltage-clamp recordings in coronal brainstem slices from the neonate. Facial motoneurons were identified by antidromic invasion following electrical stimulation of the genu of the facial nerve. When the membrane potential was held at or near its resting level, vasopressin generated an inward current whose magnitude was concentration related; the lowest peptide concentration still effective in eliciting this effect was $10 \mathrm{~nm}$. The vasopressin-induced current, $I_{\text {AvP }}$, was resistant to tetrodotoxin (TTX) and was insensitive to a reduction in extracellular calcium concentration. It was sustained, was inward at all potentials tested ( -120 to $-25 \mathrm{mV}$ ), and increased in magnitude during depolarization. $I_{\mathrm{AVP}}$ was not generated by the blockade of a potassium current, because it did not reverse at hyperpolarized potentials, was not affected by a two-fold increase in the transmembrane potassium gradient, and was not modified by the potassium channel blockers tetraethylammonium bromide (TEA), 4-aminopyridin (4-AP), barium, cesium, quinine, glibenclamide, and apamin. Also, $I_{\text {AVP }}$ was not affected by changes in the transmembrane chloride gradient. In contrast, it could be reduced by partially substituting extracellular sodium with equimolar $\mathbf{N}$-methylD-glucamine or Tris. Our results suggest that vasopressin increases the excitability of facial motoneurons by generating a persistent sodium-dependent membrane current that is voltage gated and TTX resistant.

The nonapeptide arginine vasopressin, which is synthesized in the hypothalamus and secreted into the circulation at the level of the neurohypophysis, exerts a variety of peripheral effects. Thus, by acting on $\mathrm{V}_{1}$-type, phospholipase $\mathrm{C}$-coupled receptors, it causes vasoconstriction and stimulates glycogenolysis in hepatocytes; by binding to $\mathrm{V}_{2}$-type, adenylate cyclase-coupled receptors, it enhances water reabsorption in the kidney (Jard, 1983; Manning et al., 1987). Immunocytochemical, autora-

Received Oct. 1, 1990; revised Jan. 2, 1991; accepted Jan. 4, 1991.

This work was supported in part by Grant 31.28624.90 from the Swiss National Science Foundation. We thank Dr. M. M. Manning for the gift of the selective oxytocin agonist, Dr. D. Bertrand for helpful discussions, and Mrs. D. Machard for excellent technical assistance.

Correspondence should be addressed to Mario Raggenbass, Ph.D., Département de Physiolcgie, Centre Médical Universitaire, 9 Avenue de Champel, CH-1211 Genève, Switzerland.

Copyright (C) 1991 Society for Neuroscience $0270-6474 / 91 / 111609-08 \$ 03.00 / 0$ diographical, and biochemical studies have suggested that vasopressin probably also plays a role as a neurotransmitter/ neuromodulator (Audigier and Barberis, 1985; Buijs, 1987; Dubois-Dauphin and Zakarian, 1987; Van Leeuwen, 1987; FreundMercier et al., 1988; Poulin et al., 1988; Tribollet et al., 1988), and on the basis of behavioral studies, it has been claimed that this peptide may influence memory storage and retrieval (De Wied, 1980). Electrophysiological studies have indicated that vasopressin can directly excite selected populations of central neurons (Suzue et al., 1981; Mühlethaler et al., 1982; Ma and Dun, 1985; Peters and Kreulen, 1985; Raggenbass et al., 1987, 1988, 1989; Carette and Poulain, 1989; Liou and Albers, 1989; Sun and Guyenet, 1989). Although some information is available concerning the cellular mode of action of vasopressin as a hormone (Mollard et al., 1988; Van Renterghem et al., 1988; Korbmacher et al., 1989; Martin et al., 1989), the membrane mechanism by which vasopressin affects neuronal bioelectrical activity is not yet known. We have approached this problem by recording from vasopressin-sensitive facial motoneurons from the newborn rat (Tribollet et al., 1991), using the in vitro brain slice technique and the single-electrode voltage-clamp method.

\section{Materials and Methods}

Intracellular recordings. The animals used were 2-10-d-old male rats from a Sprague-Dawley-derived strain. Coronal brainstem slices, 300$400 \mu \mathrm{m}$ thick, were cut using a vibratome, transferred to a recording chamber, and perfused, at $34-35^{\circ} \mathrm{C}$, with a solution containing (in $\mathrm{mm}$ ) $135 \mathrm{NaCl}, 15 \mathrm{NaHCO}_{3}, 1 \mathrm{MgSO}_{4}, 1.25 \mathrm{KH}_{2} \mathrm{PO}_{4}, 2 \mathrm{CaCl}_{2}, 10$ glucose, and, unless otherwise stated, $5 \mathrm{KCl}$. This solution was saturated with $95 \% \mathrm{O}_{2} / 5 \% \mathrm{CO}_{2}(\mathrm{pH}, 7.35-7.45)$. A low-calcium, high-magnesium solution, containing $0.1 \mathrm{mM} \mathrm{CaCl}_{2}$ and $16 \mathrm{mM} \mathrm{MgSO}_{4}$, was used in some experiments to block synaptic transmission and to reduce membrane calcium currents. When barium was added to the solution, phosphates were omitted, and $\mathrm{MgSO}_{4}$ was replaced by $\mathrm{MgCl}_{2}$. $N$-methyl-D-glucamine and Tris, which were used in sodium ion substitution experiments, were titrated to $\mathrm{pH} 7.4$ with concentrated $\mathrm{HCl}$. Microelectrodes contained either $3 \mathrm{M} \mathrm{KCl}$ or $3 \mathrm{M} \mathrm{K}$-acetate $(\mathrm{pH}, 7.4 ; 30-80 \mathrm{M} \Omega)$; in some experiments, facial neurons were cesium-loaded by impalement with microelectrodes filled with $2 \mathrm{M} \mathrm{CsCl}$ or Cs-acetate $(\mathrm{pH}, 7.4)$. Recordings were done using an Axoclamp-2A amplifier. In the single-electrode voltage-clamp mode, the switching frequency was $2-3 \mathrm{kHz}$, and the headstage was continuously monitored. Membrane potential and current were plotted on paper on line. Some data were digitized using a homemade A/D converter and stored on the hard disk of an IBM-ATcompatible computer for further analysis. Antidromic activation of facial neurons was achieved by delivering constant current pulses (10$100 \mu \mathrm{A}, 0.1 \mathrm{msec})$ to the genu of the facial nerve. The elicited action potentials were considered to be due to antidromic invasion if (1) they arose at fixed latency following stimulation, (2) they followed highfrequency stimulation, and (3) they could dissociate, in double-shock studies, into initial segment and somatodendritic components.

Light microscopic autoradiography. Following dissection, brain tissue was frozen in 2 -methylbutane at $-25^{\circ} \mathrm{C}$. Series of $15-\mu \mathrm{m}$-thick sections were cut in a cryostat, mounted on gelatin-coated slides, and, after 
Figure 1. Vasopressin binding sites in the facial nucleus of a newborn rat. Autoradiograms in $A$ and $B$ were obtained by incubating coronal brainstem sections with ${ }^{3} \mathrm{H}$-vasopressin $(A)$ or with ${ }^{3} \mathrm{H}$-vasopressin supplemented with an excess of nonradioactive vasopressin (B). $C$ and $D$ show the ventrolateral region on the right side of $A$ at a higher magnification. $D$ is the cresyl violetstained section used to generate autoradiograms $A$ and $C$. Note that labeling is most intense in the area containing large facial-motoneuron perikarya. Scale bars: $A$ and $B, 1 \mathrm{~mm} ; C$ and $D, 0.5 \mathrm{~mm}$.
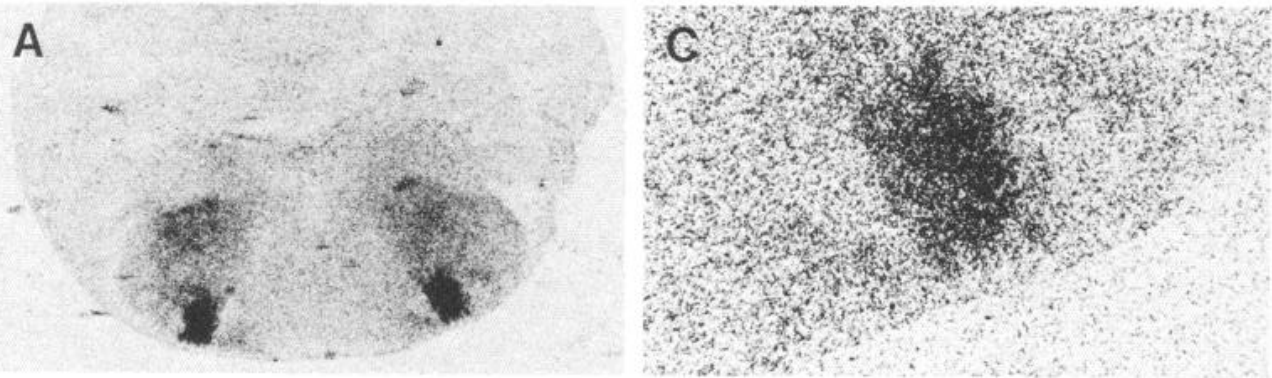

B

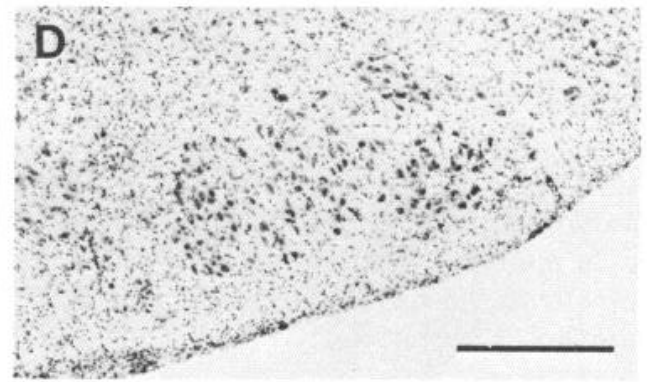

drying, stored at $-80^{\circ} \mathrm{C}$. Prior to the binding procedure, the sections were slightly fixed for $5 \mathrm{~min}$ in $0.2 \%$ paraformaldehyde in phosphatebuffered saline (PBS; $\mathrm{pH}, 7.4$ ). Each slide was incubated for $1 \mathrm{hr}$ at room temperature in $400 \mu \mathrm{l}$ of a solution containing $50 \mathrm{~mm}$ Tris- $\mathrm{HCl}$ $(\mathrm{pH}, 7.4), 0.025 \%$ bacitracin, $5 \mathrm{~mm} \mathrm{MgCl}_{2}$, and $0.1 \% \mathrm{BSA}$ and supplemented with $3 \mathrm{nM}^{3} \mathrm{H}$-vasopressin and $5 \mathrm{nM} \mathrm{HO}\left[\mathrm{Thr}^{4}, \mathrm{Gly}^{7}\right]$ oxytocin. The presence of this last compound, a selective oxytocin agonist, prevented the labeling by ${ }^{3} \mathrm{H}$-vasopressin of oxytocin binding sites. In order to determine non-specific binding, adjacent sections were incubated in the same solution as above but supplemented with $1 \mu \mathrm{M}$ nonradioactive vasopressin. The slides were washed in ice-cold medium, rinsed in distilled water, dried, and placed in contact with tritium-sensitive films in an $\mathrm{x}$-ray cassette for 3-4 months. Films were developed for $5 \mathrm{~min}$ in Kodak D19, and sections were stained with cresyl violet.

Chemical compounds. Vasopressin (8-L-arginine vasopressin) was purchased from Bachem (Bubendorf, Switzerland). ${ }^{3} \mathrm{H}$-vasopressin (specific activity, $67 \mathrm{Ci} / \mathrm{mmol}$ ) was from Du Pont-New England Nuclear (Boston, MA) and was purified by HPLC and affinity chromatography (Pradelles et al., 1972). The oxytocic-selective agonist HO[Thr $\left.{ }^{4}, \mathrm{Gly}^{7}\right]$ oxytocin ([1-(L-2-hydroxy-3-mercaptopropionic acid),4-threonine,7-glycine]oxytocin; Lowbridge et al., 1977) was kindly provided by Dr. M. M. Manning (Department of Biochemistry, Medical College of Ohio, Toledo, OH). Tetrodotoxin (TTX), glibenclamide, apamine, and quinine hydrochloride were from Sigma (St. Louis, MO). Tetraethylammonium bromide (TEA), 4-aminopyridin (4-AP), Na-isethionate, and $\mathrm{N}$-methyl-D-glucamine were from Fluka (Buchs, Switzerland).

\section{Results}

The facial nucleus of the newborn rat, and particularly its intermediate part, contains specific, high-affinity binding sites for ${ }^{3} \mathrm{H}$-vasopressin (Fig. 1). The density of these sites is maximal shortly after birth and decreases during the third week of postnatal life; no binding sites can be detected in the adult animal. At least part of these sites represent functional neuronal receptors, whose pharmacological profile is indistinguishable from that of $V_{1}$ (vasopressor-type) peripheral receptors (Tribollet et al., 1991). Because facial motoneurons can be stably impaled due to their large dimensions, we chose to study the membrane mechanism underlying the neuronal action of vasopressin by recording from these cells in brainstem slices from newborn rats.

Intracellular recordings were obtained from 193 neurons located in the region of the facial nucleus in slices from 66 animals.
These cells had resting membrane potentials negative to -50 $\mathrm{mV}$ and fired no action potentials at rest. Their average input resistance was $25 \pm 12 \mathrm{M} \Omega$ (mean $\pm \mathrm{SD} ; n=180$ ). Eightyseven neurons could be activated antidromically following electrical stimulation of the genu of the facial nerve and were thus identified as facial motoneurons (Fig. $2 B$ ). The average input resistance of these identified motoneurons was $25 \pm 11 \mathrm{M} \Omega$ (mean $\pm \mathrm{SD} ; n=84$ ). Vasopressin, dissolved in the perfusion solution, affected $82 \%$ of the recorded neurons. Of the identified motoneurons, $84 \%$ responded to the peptide. When the membrane potential was voltage clamped at or near its resting level, vasopressin generated a sustained inward current (Fig. $2 A$ ); under current-clamp conditions, the peptide caused a membrane depolarization (see Fig. $5 B$ ). These effects were fully reversible. The peak current evoked by vasopressin, added to the perfusion solution at $1 \mu \mathrm{M}$ for $30 \mathrm{sec}$, ranged from 0.1 to $1.4 \mathrm{nA}$, and the peak depolarization ranged from 3 to $20 \mathrm{mV}$. The action of vasopressin was concentration dependent, the lowest peptide concentration still effective in eliciting an effect being $10 \mathrm{~nm}$ (except in one neuron, where a measurable effect was evoked by vasopressin at $1 \mathrm{~nm}$; see Fig. $2 A$ ). Thus, at $10 \mathrm{~nm}, 100 \mathrm{~nm}$, and $1 \mu \mathrm{M}$, the vasopressin-induced peak current was $0.08 \pm$ $0.02,0.31 \pm 0.07$, and $0.63 \pm 0.12 \mathrm{nA}$ (mean $\pm \mathrm{SEM} ; n=4$ ) respectively, and the evoked peak depolarization was $2.2 \pm 0.4$, $7.6 \pm 1.2$, and $12 \pm 2.4 \mathrm{mV}$ (mean $\pm \mathrm{SEM} ; n=5$ ), respectively. No tachyphylaxis was observed upon repeated application of vasopressin.

The effect of vasopressin was insensitive to TTX present in the perfusion solution at $0.5-2 \mu \mathrm{M}$ (see Fig. 3; tested on 30 neurons); at these toxin concentrations, sodium-dependent action potentials were abolished. The peptide effect persisted when the normal solution was replaced with a low-calcium, highmagnesium solution (Fig. $2 B$; tested on eight neurons). During perfusion with the latter solution, transmembrane calcium currents were greatly reduced, as indicated by the disappearance of TTX-resistant action potentials and of evoked synaptic potentials. Thus, the action of the peptide is postsynaptic, and the vasopressin-induced response is probably not due to the activation either of a TTX-sensitive sodium current or of a calcium current. 
Facial neurons were voltage clamped, and current-voltage $(I / V)$ relations were determined by measuring the total membrane current at the end of voltage command steps lasting $0.5-$ 1 sec delivered before, during, and after the peptide-induced response (see Fig. $3 A_{1}$ ). The vasopressin-induced current, $I_{\mathrm{AvP}}$, was computed by subtracting the control $I / V$ curve from the curve obtained in the presence of the peptide (see Fig. $3 A_{2}$ ). In 16 out of 25 sensitive neurons, vasopressin affected the $I / V$ relation by causing an apparent increase in membrane resistance, which was most pronounced at depolarizing voltage steps (Fig. $3 \mathrm{~A}_{1}$ ). No inactivation of $I_{\mathrm{AVP}}$ could be detected over the duration of the voltage steps. $I_{\mathrm{AVP}}$ was inward at all potentials tested, which ranged from -120 to $-25 \mathrm{mV}$, and the magnitude of this current increased progressively as the potential was displaced in the depolarizing direction (Fig. $3 A_{2}, B$ ).

Command steps to potentials positive to $-20 \mathrm{mV}$ evoked powerful outward currents, which were often unstable and which could be reduced, but not suppressed, by perfusing a cocktail of potassium channel blockers and a low-calcium, high-magnesium solution. At these potentials, $I_{\mathrm{AVP}}$ could not be reliably measured by the subtraction method illustrated in Figure 3.

The voltage dependence of $I_{\mathrm{AvP}}$ might suggest that vasopressin acted by blocking an outward current whose reversal potential is more negative than the resting membrane potential (i.e., a potassium or a chloride current). Three lines of evidence indicate, however, that a potassium current is probably not implicated in the vasopressin effect: (1) As stated above, $I_{\mathrm{AvP}}$ did not reverse in polarity at hyperpolarized potentials (see Fig. $3 A_{2}, B$ ). (2) In seven out of seven neurons, which were current or voltage clamped at their resting membrane potential, the responses to vasopressin recorded in $3.25 \mathrm{~mm}$ and $7.25 \mathrm{~mm}$ extracellular potassium were superposable. (3) None of several potassium channel blockers (Castle et al., 1989; Dreyer, 1990) could suppress the response to vasopressin. Thus, TEA, at $10 \mathrm{~mm}$, blocked the delayed rectifier, as evidenced by the induced increase in the duration of TTX-resistant action potentials, but failed to affect the action of the peptide (see Fig. $3 A ; n=14$ ). 4-AP, at $1 \mathrm{~mm}$, enhanced the frequency and the amplitude of spontaneous synaptic potentials but did not affect the response to vasopressin (see Fig. $3 A ; n=11$ ). Barium, at $1 \mathrm{~mm}$, also had a stimulatory action on synaptic input, and cesium, at $5 \mathrm{~mm}$, suppressed a time-dependent inward rectifier, but neither cation had any effect on the peptide-induced current $(n=10)$. Moreover, vasopressin responsiveness was still present in 8 out of 11 cesium-loaded facial motoneurons (Fig. 4). Quinine, at $200 \mu \mathrm{M}$, did not interfere with the vasopressin-induced response $(n=4)$. Glibcnclamide, a blocker of ATP-sensitive potassium channels, at $1 \mu \mathrm{M}(n=5)$, and apamin, a blocker of small-conductance calcium-dependent potassium channels, at $50 \mathrm{~nm}(n=4)$, were also without effect on the peptide-evoked current.

Twelve vasopressin-sensitive facial neurons were recorded using micropipettes filled with $\mathrm{KCl}$ instead of $\mathrm{K}$-acetate. Following impalement, spontaneous IPSPs were converted to depolarizing potentials, indicating that the transmembrane chloride gradient had been reversed. However, the polarity of the response to vasopressin, determined during either current- or voltage-clamp recordings, was similar to that observed when using K-acetate-filled micropipettes. Moreover, the effect of the peptide was not modified when $60 \%$ of external $\mathrm{NaCl}$ was replaced by an equimolar amount of $\mathrm{Na}$-isethionate (tested on three neurons). This indicates that a chloride current does not contribute significantly to the vasopressin-induced response.
A
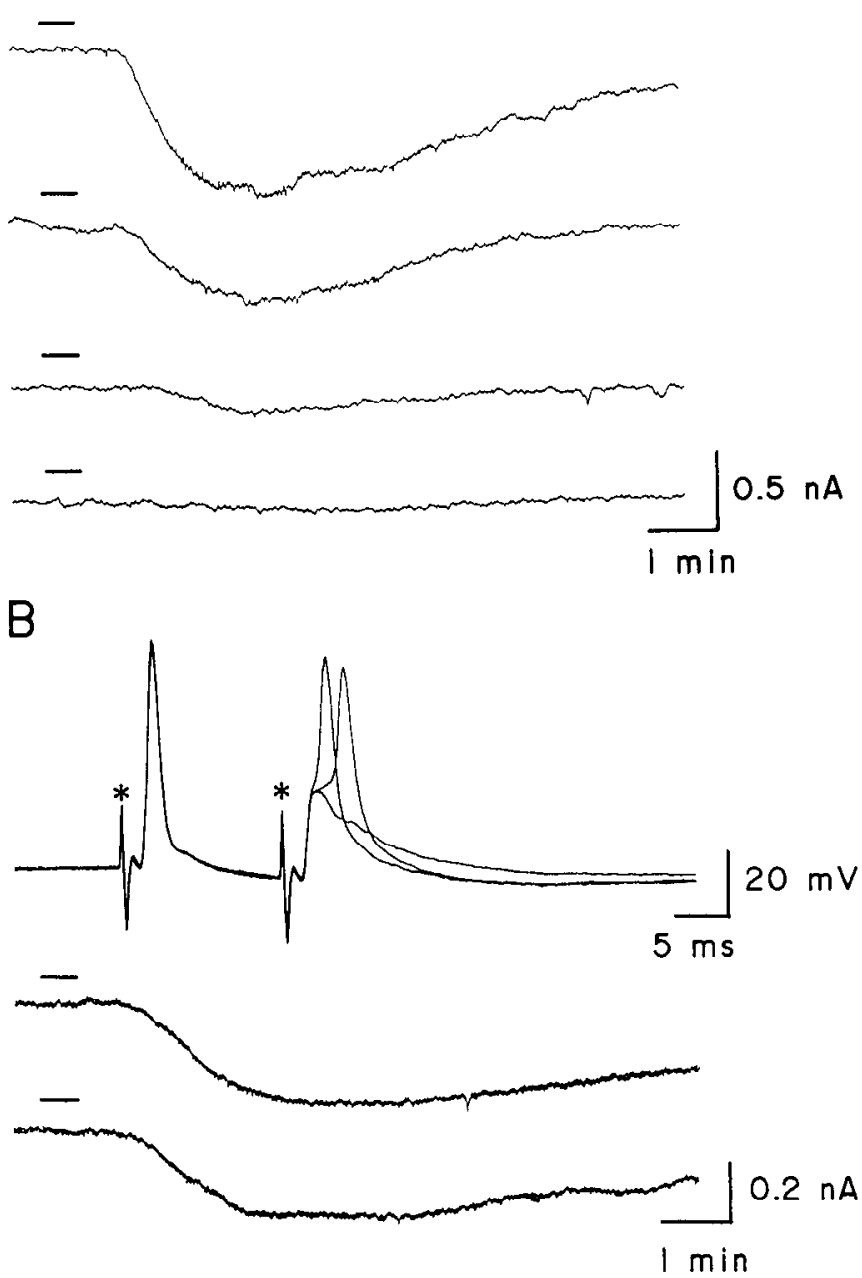

Figure 2. Concentration-dependent effect of vasopressin on a voltageclamped facial neuron $(A)$ and lack of effect of a change in extracellular calcium concentration on the vasopressin-induced response in an antidromically identified facial motoneuron $(B) . A$, Voltage-clamp records of the membrane current activated by vasopressin at $1 \mu \mathrm{M}$ and 100,10 , and $1 \mathrm{nM}$, from top to bottom. The horizontal bar above each record indicates the time during which the peptide was added to the perfusion solution. The holding potential was $-62 \mathrm{mV}$. B: Upper traces, Three superimposed current-clamp records, showing the neuronal response to pairs of shocks delivered to the genu of the facial nerve at 14-msec intervals. The stimulus artifacts are marked by asterisks. Note that, following the second stimulus in each pair, the evoked action potential dissociated into initial segment and somatodendritic components; due to refractoriness of the soma, the latter component was absent from some of the records. This indicates that action potentials were evoked by antidromic invasion of the neuronal soma. During these recordings, the preparation was perfused with the normal solution. Middle and lower traces, Voltage-clamp records from the same neuron, showing the current generated by $1 \mu \mathrm{M}$ vasopressin during perfusion with the normal solution and with a low-calcium, high-magnesium solution, respectively. Holding potential, $-61 \mathrm{mV}$.

$I_{\text {Avp }}$ could be an inward current whose reversal potential is positive to the resting membrane potential. In this case, however, in order to account for its voltage dependence (see Fig. $\left.3 A_{2}, B\right), I_{\mathrm{AvP}}$ has to be voltage gated: Its activation would be weak, or negligible, at hyperpolarized potentials and would increase following depolarization. Because calcium ions do not contribute significantly to the response to vasopressin (see above), 
Al

Figure 3. Voltage dependence of the vasopressin-specific current. $A_{i}$, Superimposed current responses, evoked by 750-msec voltage command steps (bottom panel), and recorded in the absence (top panel), in the presence (second pan$e l$ ), and following washout of $1 \mu \mathrm{M}$ vasopressin (third panel). Note that the action of the peptide was accompanied by an apparent increase in membrane resistance and that this effect was more pronounced at depolarized voltage levels. The recordings were carried out while the preparation was perfused with a solution containing $1 \mu \mathrm{M}$ TTX, $10 \mathrm{mM}$ TEA, and $1 \mathrm{~mm}$ 4-AP. The neuron was clamped at its resting membrane potential, $-75 \mathrm{mV}$; the holding current in the presence of vasopressin attained $-0.2 \mathrm{nA} . A_{2}, I / V$ relations determined before (open squares), during (open circles), and after (open triangles) the peptide-induced effect. Each point represents the total current flowing through the membrane at the end of each of the 750 -msec voltage steps shown in $A_{i}$. The vasopressin-specific current, $I_{A V P}$ (solid circles), was obtained by subtracting the control $I / V$ curve from the curve determined in the presence of the peptide. $B, I_{\text {Avp }}$ from a sample of four further neurons, represented by solid squares, diamonds, circles, and triangles, respectively. The perfusion solutions contained $1 \mu \mathrm{MTTX}$; in one case, $10 \mathrm{~mm}$ TEA was also added (solid triangles). Note, in $A_{2}$ and $B$, that $I_{\mathrm{Avp}}$ was inward over the entire range of potentials tested and incrcased in magnitude as the membrane was depolarized; in one case, it apparently began to decrease in magnitude at potentials positive to $-40 \mathrm{mV}(B$, solid diamonds).

B
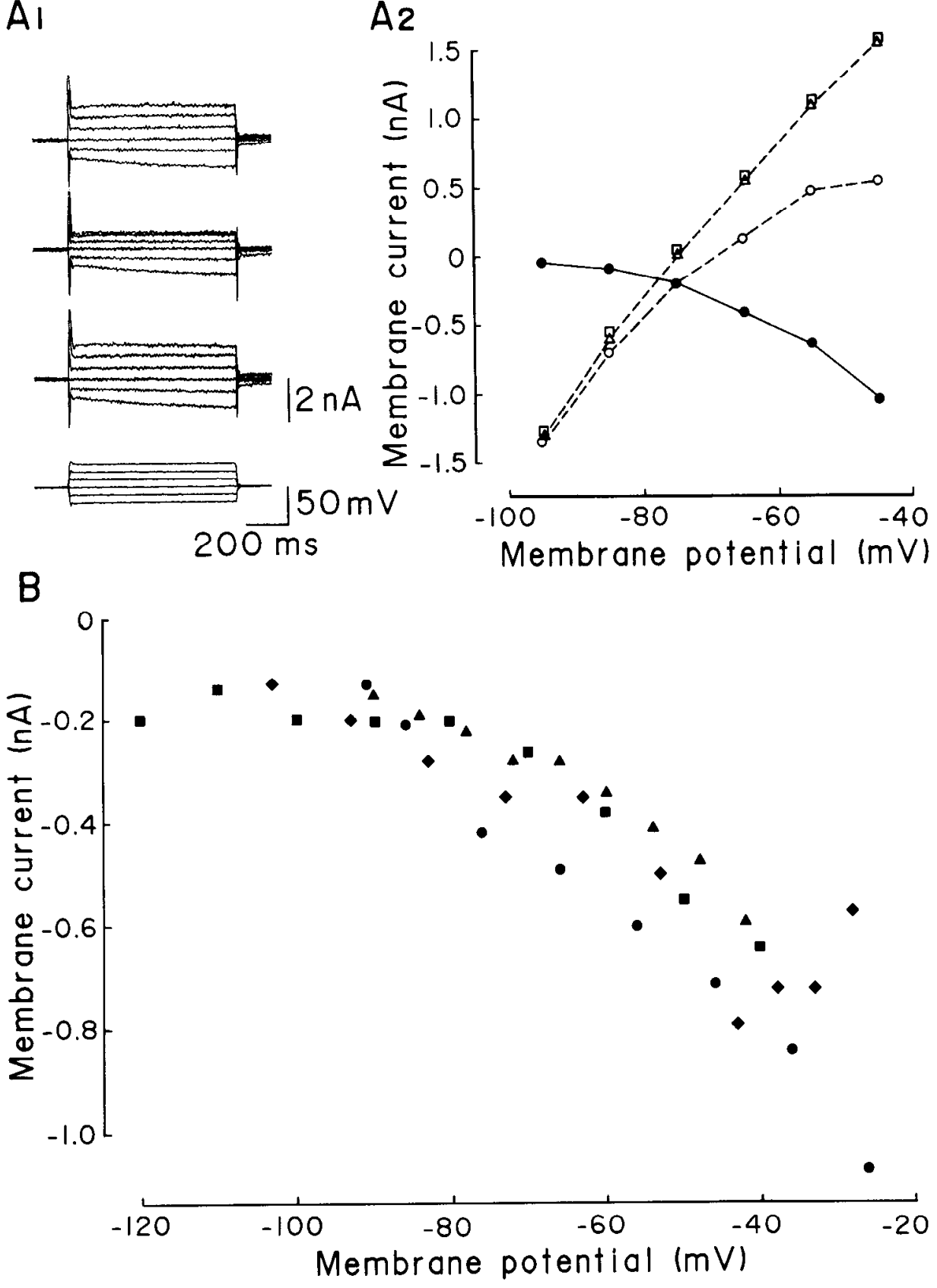

$I_{\text {Avp }}$ could be a sodium current. To test this hypothesis, we compared the peptide-induced response recorded in the physiological solution with that recorded in the presence of reduced extracellular sodium concentration. When $54 \%$ sodium was replaced by equimolar $N$-methyl-D-glucamine, or when $45 \%$ sodium was replaced by equimolar Tris, the vasopressin-induced peak current decreased reversibly by $40-50 \%$ (Fig. $5 A ; n=7$ ). Substitution of $72 \%$ sodium with equimolar amounts of either $\mathrm{N}$-methyl-D-glucamine or Tris resulted in a $60-85 \%$ reduction of the response to vasopressin, recorded under either currentor voltage-clamp conditions (Fig. $5 B ; n=8$ ). The effectiveness of these ionic substitutions was certified by the fact that, during low-sodium perfusion, action potentials, evoked by antidromic invasion or by intracellular current injection, had a reduced amplitude or even disappeared. These data show that $I_{\text {AVP }}$ is sodium dependent. Because the reversal potential of this current is not known, they do not indicate whether it is a pure sodium current or a mixed sodium-potassium current. However, while a two- to three-fold reduction in the transmembrane sodium gradient greatly reduced the response to vasopressin, a more than two-fold reduction in the transmembrane potassium gradient did not affect it (see above). This suggests, though does not prove, that the current generated by this peptide is mainly carried by sodium ions.

\section{Discussion}

We have found that in facial motoneurons from the newborn rat the neuropeptide vasopressin can generate a sodium current that is voltage gated, noninactivating (or very slowly inactivating), and TTX resistant. To our knowledge, it is the first time 

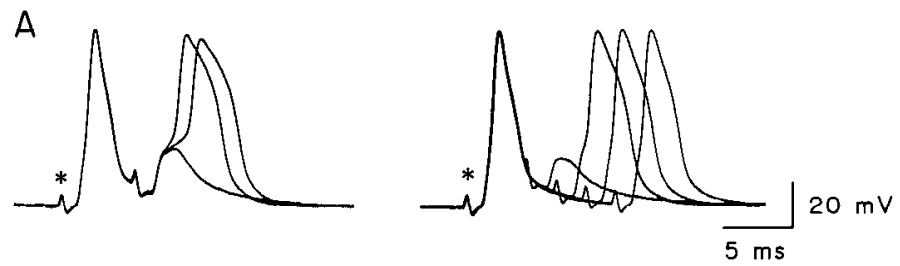

B
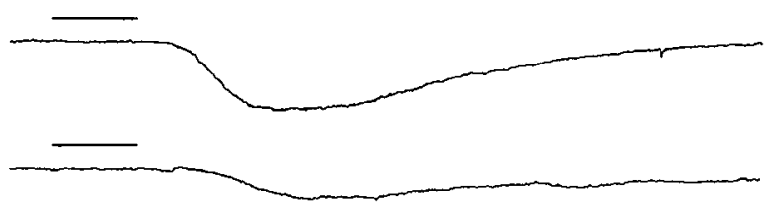

$0.5 \mathrm{nA}$
A

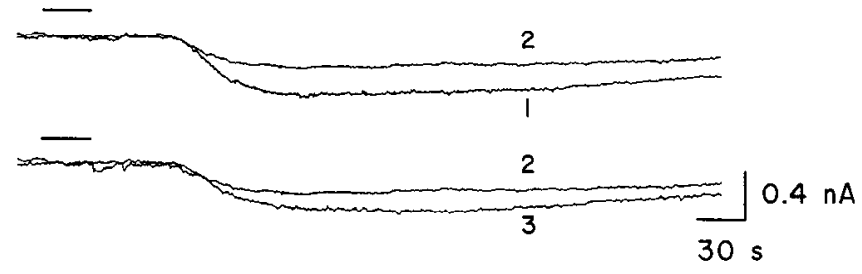

B

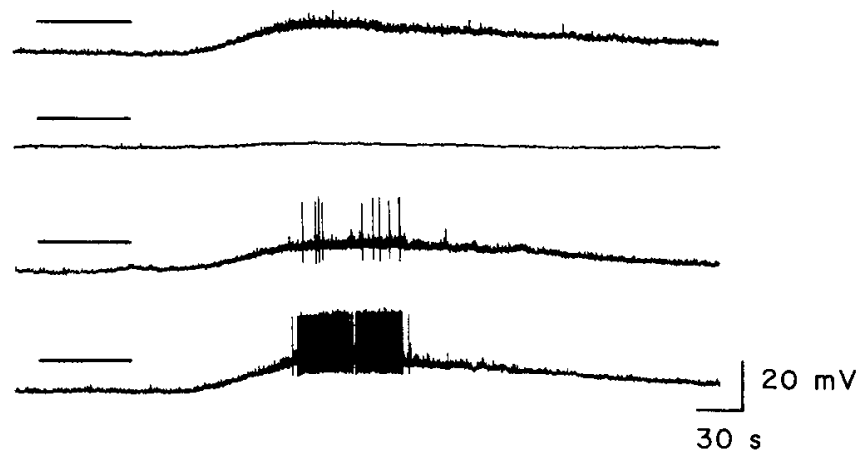

Figure 5. Effects of changes in the extracellular sodium concentration on two facial neurons $(A$ and $B$ ). $A$, Voltage-clamp records of the membrane current induced by $1 \mu \mathrm{M}$ vasopressin in the normal solution (trace 1), in a solution in which $54 \%$ of extracellular sodium was replaced by equimolar $N$-methyl-D-glucamine (trace 2 ), and $6 \mathrm{~min}$ after perfusing the preparation with the normal solution again (trace 3.) The horizontal bar above each record indicates the time during which the peptide was added to the perfusion solution. Holding potential, $-55 \mathrm{mV}$. $B$, Currentclamp records showing the membrane depolarization induced by $1 \mu \mathrm{M}$ vasopressin in the normal solution (top trace), following substitution of $72 \%$ extraccllular sodium with equimolar $N$-methyl-D-glucamine (second trace), and $7 \mathrm{~min}$ (third trace) or $28 \mathrm{~min}$ (bottom trace) after reintroducing the normal perfusion solution. Resting membrane potential, $-61 \mathrm{mV}$. Action potentials in the third and bottom traces are truncated due to the low-frequency response of the oscillograph. Note that, in both $A$ and $B$, lowering the extracellular sodium concentration caused a reversible reduction in the amplitude of the vasopressin-induced response. Note also, in $B$, the reversible disappearance of spontaneous synaptic potentials during perfusion with the low-sodium solution.

conductance values are represented by the solid circles in Figure 6 , top. (In assuming $V_{r}=60 \mathrm{mV}$, we have postulated, quite arbitrarily, that $I_{\mathrm{AVP}}$ is a pure or nearly pure sodium current. Provided it is much more positive than the resting membrane potential, the exact value of $V_{r}$ does not affect the qualitative outcome of the simulation procedure. However, it influences the value of the parameters $V_{0}$ and $V_{s}$.) As a second step, the best-fit curve to the conductance values is generated using Equation 1, with $g_{\max }=15 \mathrm{nS}, V_{0}=-51 \mathrm{mV}$, and $V_{s}=11 \mathrm{mV}$. This curve is represented by the solid line in Figure 6, top. As a last step, the theoretical peptide-induced current is computed by solving Equation 2 with respect to $I$. This computed current is plotted in Figure 6, bottom (solid line), together with the experimental values of $I_{\text {AVP }}$ (solid circles).

The result of the curve fitting suggests that the amplitude of $I_{\mathrm{AVP}}$ is regulated by the voltage-dependent gating of an ionic channel that can be in one of two states, open or closed. Because the slope factor $V_{s}$ is given by $k T / e z$, where $k$ is the Boltzmann contant; $T$, the absolute temperature; $e$, the elementary charge; and $z$, the gating charge for opening the channel, and because

where $I$ is the membrane current, and $V_{r}$, its reversal potential, which is assumed to be $60 \mathrm{mV}$ for $I_{\mathrm{AVP}}$. The calculated chord- 

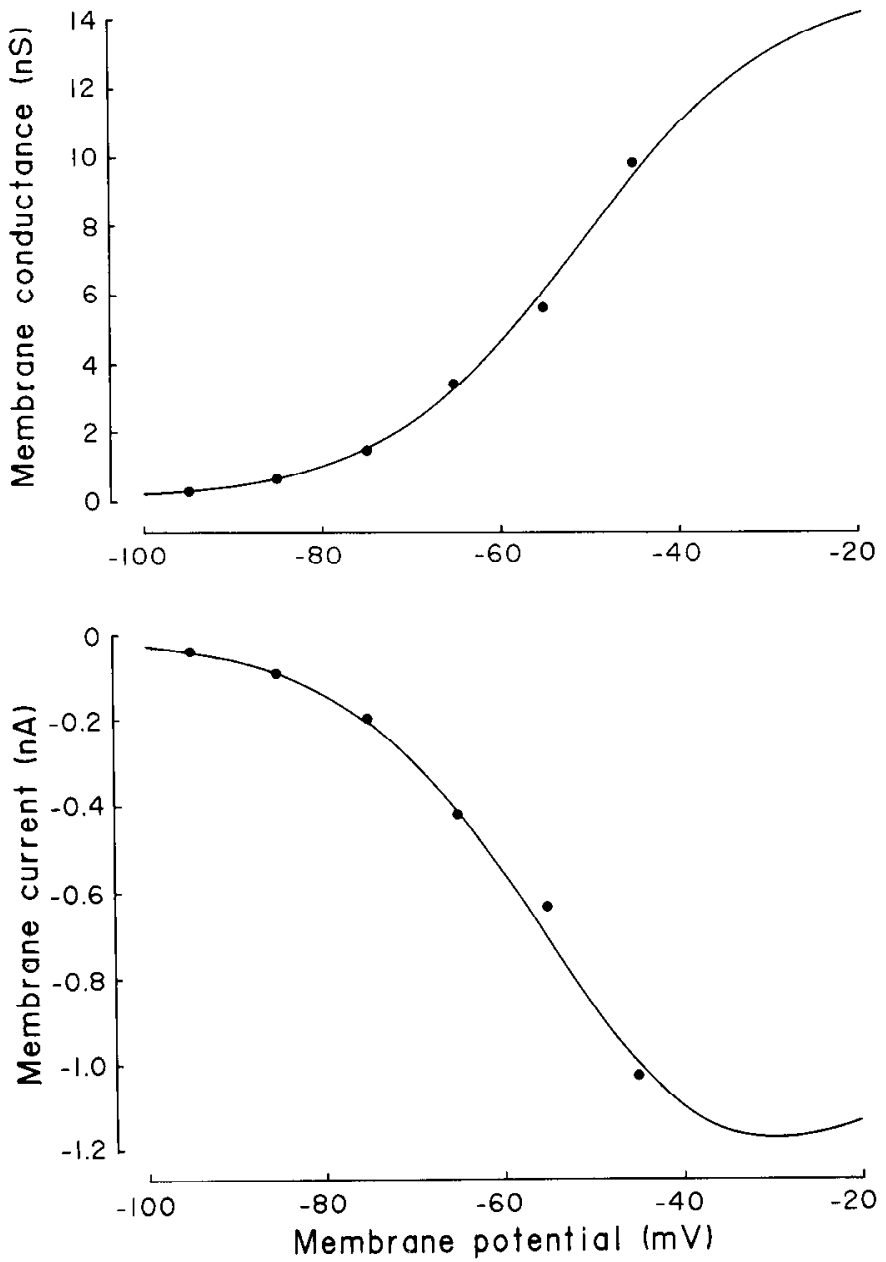

Figure 6. Mathematical simulation of the vasopressin-induced conductance change (solid line, top) and membrane current (solid line, bottom) as a function of the membrane potential. The solid circles are data points obtained for the neuron of Figure $3 A$ and represent the vasopressin-induced change in chord conductance (top) and the vasopressininduced membrane current, $I_{\mathrm{AVP}}$ (bottom). The best-fit curves were computed by assuming that the voltage dependence of the vasopressinsensitive conductance obeys the Boltzmann equation. For a detailed description of the calculations, see Discussion.

at $35^{\circ} \mathrm{C}, k T / e=26.5 \mathrm{mV}$, by taking $V_{s}=11 \mathrm{mV}$ (see above) one can estimate that the gating charge is equivalent to about 2.5 elementary charges. By virtue of its voltage dependence, $I_{\mathrm{AVP}}$ could play a role in amplifying, in a self-reinforcing manner, depolarizing signals induced by synaptic currents. Because of its persistence, $I_{\mathrm{Avr}}$ could also contribute to the generation of sustained depolarizing potentials and/or modulate the repetitive firing of facial motoneurons. More detailed biophysical and functional studies of the membrane properties of facial motoneurons are needed in order to test these conjectures.

An early attempt to characterize the mode of action of vasopressin was carried out in supraoptic neurons from the guinea pig (Abe et al., 1983). Vasopressin could depolarize these neurons, but contrary to what was found in the present work, this effect was independent of voltage and was not accompanied by any change in membrane resistance. It was not affected by changes in extracellular calcium, potassium, or chloride and was only slightly reduced following sodium depletion.

Noninactivating or slowly inactivating sodium-dependent currents have been detected in some mammalian neurons, including cerebellar Purkinje cells, inferior olive neurons, neocortical neurons, and hippocampal pyramidal neurons (French et al., 1990; for a recent review, see Llinas, 1988). These currents, which are enhanced by membrane depolarization, are blocked by micromolar concentrations of TTX and do not require the presence of an agonist in order to be activated. They are thus different from the vasopressin-induced current characterized in the present work. TTX-resistant sodium currents have been recorded in denervated skeletal muscle cells (Harris and Thesleff, 1971; Paponne, 1980) as well as in muscle cells developing in vitro (Frelin et al., 1984; Gonoi et al., 1985; Weiss and Horn, 1986). Contrary to $I_{\mathrm{AVP}}$, however, these currents inactivate rapidly, with time constants comparable to those of TTX-sensitive sodium currents in innervated adult muscle.

Sodium-dependent, TTX-resistant currents have been characterized in invertebrate neurons and, more recently, also in some mammalian central neurons. Thus, the egg-laying hormone (ELH) of Aplysia excites an identified motoneuron in this species by inducing a persistent inward current that is not affected by changes in extracellular calcium, potassium, or chloride concentrations, is resistant to potassium channel blockers, and is reduced, or suppressed, when extracellular sodium is lowered (Kirk and Scheller, 1986). This current has a negative slope between -40 and $-25 \mathrm{mV}$ and reverses at potentials ranging from -28 to $+46 \mathrm{mV}$. It bears some striking similarities to $I_{\mathrm{Avp}}$. The tetrapeptide FMRFamide and the vasopressin-related peptide oxytocin can elicit, in Aplysia and in the snail Achatina fulica, respectively, a slow inward, voltage-dependent current largely carried by sodium (Ichinose and McAdoo, 1988; Funase, 1990). At variance with both $I_{\mathrm{AVP}}$ and the ELH-induced current, these currents are modulated by extracellular calcium ions. Persistent, voltage-dependent sodium currents can also be activated by intracellular injection of cAMP or cGMP in neurons from several gastropod species (Green and Gillette, 1983; Connor and Hockberger, 1984). Interestingly, lysine vasopressin can induce a bursting activity in a neuron of the land snail Otala by eliciting a voltage-dependent, slowly inactivating inward current (Barker and Smith, 1976); however, the ionic nature of this current has not been determined. Recording from locus coeruleus neurons in rat brain slices, Wang and Aghajanian (1987) found that 8-Br-cAMP, a membrane-permeable analog of cAMP, and forskolin, an activator of adenylate cyclase, elicited a current that was inward over the potential range of -120 to $-50 \mathrm{mV}$, was accompanied by a slight increase in conductance, was resistant to TTX and to calcium channel blockers, and was reduced by decreasing extracellular sodium concentration. In these same neurons, vasoactive intestinal peptide (VIP) generated a similar inward current (Wang and Aghajanian, 1990). The effects of cAMP-active agents and of VIP were nonadditive and were both attenuated by a specific protein inhibitor of CAMPdependent protein kinase, suggesting that the VIP-induced inward current was mediated by cAMP.

Though the intracellular events associated with the electrophysiological effect of vasopressin on facial motoneurons have yet to be elucidated, the existence of points of similarity between $I_{\mathrm{AVP}}$ and cyclic-nucleotide-dependent slow sodium current raises the possibility that vasopressin may exert its neuronal action by activating a receptor-coupled adenylate cyclase. In accordance with this conjecture, Abe et al. (1983) reported that dibutyryl cAMP could mimick the depolarizing effect of vasopressin on guinea pig supraoptic neurons and that the content 
of cAMP in hypothalamic slices increased following incubation with the peptide. These findings, however, have not been confirmed by other workers. By binding to $\mathrm{V}_{1}$-type receptors, vasopressin strongly activated the metabolism of inositol phospholipids without affecting cAMP concentration in superior cervical ganglia of the rat (Bone et al., 1984; Kiraly et al., 1986) and caused a moderate increase in phosphoinositide hydrolysis in rat hippocampus (Stephens and Logan, 1986), medulla oblongata (Moratalla et al., 1988), and septum (Shewey and Dorsa, 1988; Lebrun et al., 1990). Thus, most of the existing evidence supports the notion that the interaction of agonist with $V_{1}$ vasopressin receptors present in the nervous system leads to the activation of a phospholipase $\mathrm{C}$, as is the case in the periphery (Jard, 1983). One should keep in mind, however, that vasopressin could indirectly influence cAMP metabolism. Thus, vasopressin facilitated the stimulation of adenylate cyclase activity by dopamine in the rat caudate nucleus but had no effect per se on the activity of this enzyme (Courtney and Raskind, 1983). In pituitary corticotrophs, vasopressin triggered an increase in cytosolic calcium and stimulated phosphoinositide turnover, yet it potentiated the cAMP production induced by corticotropinreleasing factor (CRF). This facilitation has been attributed to the fact that the vasopressin-activated protein kinase $C$ probably suppresses the activity of a guanine-nucleotide-binding protein, which in turn exerts an inhibitory regulatory action upon the CRF-dependent adenylate cyclase complex (Leong, 1988; Carvallo and Aguilera, 1989).

Various effects of vasopressin on membrane currents of nonneuronal cells have been recently described. The vasopressininduced stimulation of adrenocorticotropin (ACTH) from ACTH-secreting pituitary adenoma cells was accompanied by an increase in amplitude and duration of the calcium-dependent action potential fired by these cells (Mollard et al., 1988). This effect was probably due to a selective enhancement of a nifedipine-sensitive, slowly inactivating (L-type) calcium current component. Vasopressin could stimulate insulin-secreting cells by inducing a membrane depolarization and by generating calcium spikes and a rise in intracellular calcium concentration (Martin et al., 1989). These actions took place via a peptideevoked closure of ATP-sensitive potassium channels that, in these cells, are largely responsible for the maintenance of the resting membrane potential. The effects of vasopressin on both ACTH- and insulin-secreting cells are at variance with those described in the present work, because no significant contribution either of calcium currents or of potassium currents-and in particular, of ATP-sensitive potassium currents - to $I_{\text {AVP }}$ could be evidenced. Cultured aortic smooth-muscle cells have been shown to respond to vasopressin in a biphasic way, in which a transient hyperpolarization was followed by a sustained depolarization. The initial hyperpolarization was caused by the activation of a calcium-sensitive potassium conductance and by the inhibition of an L-type calcium conductance (Van Renterghem et al., 1988; Korbmacher et al., 1989). The late depolarization was associated with the opening of a channel permeable to sodium, calcium, and potassium. The inward current flowing through this nonselective cationic channel reversed at $5 \mathrm{mV}$, was not affected by changes in intracellular concentration of calcium or inositol 1,4,5-triphosphate, was not suppressed by the blockade of potassium channels, and was independent of the transmembrane chloride gradient (Van Renterghem et al., 1988). Although its voltage dependence is not known, and apart from the fact that it can in part be carried by calcium ions, this current bears some resemblance with the vasopressin-induced current characterized in the present work.

\section{References}

Abe H, Inoue M, Matsuo T, Ogata N (1983) The effects of vasopressin on electrical activity in the guinea-pig supraoptic nucleus in vitro. $\mathbf{J}$ Physiol (Lond) 337:665-685.

Audigier S, Barberis C (1985) Pharmacological characterization of two specific binding sites for neurohypophyseal hormones in hippocampal synaptic membranes of the rat. EMBO J 4:665-685.

Barker J, Smith TG Jr (1976) Peptide regulation of neuronal membrane properties. Brain Res 103:167-170.

Bone EA, Fretten P, Palmer S, Kirk CJ, Michell RH (1984) Rapid accumulation of inositol phosphates in isolated rat superior cervical sympathetic ganglia exposed to $\mathrm{V}_{1}$-vasopressin and muscarinic cholinergic stimuli. Biochem J 221:803-811.

Buijs RM (1987) Vasopressin localization and putative functions in the brain. In: Vasopressin, principles and properties (Gash DM, Boer GJ, eds), pp 91-115. New York: Plenum.

Carette B, Poulain P (1989) Vasopressin-sensitive neurons in the lateral paraventricular nucleus area in a guinea pig slice preparation. Brain Res Bull 22:969-974.

Carvallo P, Aguilera G (1989) Protein kinase C mediates the effect of vasopressin in pituitary corticotrophs. Mol Endocrinol 3:1935-1943.

Castle NA, Haylett DG, Jenkinson DH (1989) Toxins in the characterization of potassium channels. Trends Neurosci 12:59-65.

Connor JA, Hockberger P (1984) A novel membrane sodium current induced by injection of cyclic nucleotides into gastropod neurones. J Physiol (Lond) 354:139-162.

Courtney N, Raskind M (1983) Vasopressin affects adenylate cyclase activity in rat brain: a possible neuromodulator. Life Sci 32:591-596.

De Wied D (1980) Behavioral actions of neurohypophysial peptides. Proc R Soc Lond [Biol] 210:183-195.

Dreyer F (1990) Peptide toxins and potassium channels. Rev Physiol Biochem Pharmacol 115:93-136.

Dubois-Dauphin M, Zakarian S (1987) Distribution of the C-terminal glycopeptide of the vasopressin prohormone in rat brain: an immunocytochemical study. Neuroscience 21:903-921.

Frelin C, Vijverberg HPM, Romey G, Vigne P, Lazdunski M (1984) Different functional states of tetrodotoxin sensitive and tetrodotoxin resistant $\mathrm{Na}^{+}$channels occur during the in vitro development of rat skeletal muscle. Pfluegers Arch 402:121-128.

French CR, Sah P, Buckett KJ; Gage PW (1990) A voltage-dependent persistent sodium current in mammalian hippocampal neurons. J Gen Physiol 95:1139-1157.

Freund-Mercier MJ, Dietl MM, Stoeckel ME, Palacios JM, Richard P (1988) Quantitative autoradiographic mapping of neurohypophysial hormone binding sites in the rat forebrain and pituitary gland-I. Characterization of different types of binding sites and their distribution in the Long-Evans strain. Neuroscience 26:261-272.

Funase K (1990) Oxytocin-induced sodium current is mediated by cAMP-dependent protein phosphorylation in an identified snail neuron. Brain Res 517:263-268.

Gonoi T, Sherman SJ, Catterall WA (1985) Voltage clamp analysis of tetrodotoxin-sensitive and -insensitive sodium channels in rat muscle cells developing in vitro. J Neurosci 5:2559-2564.

Green JG, Gillette R (1983) Patch- and voltage-clamp analysis of cyclic AMP-stimulated inward current underlying neurone bursting. Nature 306:784-785.

Harris JB, Thesleff S (1971) Studies on tetrodotoxin resistant action potentials in denervated skeletal muscle. Acta Physiol Scad 83:382388.

Hodgkin AL, Huxley AF (1952) A quantitative description of membrane current and its application to conduction and excitation in nerve. J Physiol (Lond) 117:500-544.

Ichinose M, McAdoo DJ (1988) The voltage-dependent, slow inward current induced by the neuropeptide FMRFamide in Aplysia neuron R14. J Neurosci 8:3891-3900.

Jard S (1983) Vasopressin isoreceptors in mammals: relation to cyclic AMP-dependent and cyclic AMP-independent transduction mechanism. In: Current topics in membrane and transport: membrane receptors, Vol 18 (Kleinzeller A, ed), pp 255-285. New York: Academic.

Kiraly M, Audigier S, Tribollet E, Barberis C, Dolivo M, Dreifuss JJ (1986) Biochemical and electrophysiological evidence of functional 
vasopressin receptors in the rat superior cervical ganglion. Proc Natl Acad Sci USA 83:5335-5339.

Kirk MD, Scheller RH (1986) Egg-laying hormone of Aplysia induces a voltage-dependent slow inward current carried by $\mathrm{Na}^{+}$in an identified motoneuron. Proc Natl Acad Sci USA 83:3017-3021.

Korbmacher C, Helbig H, Stahl F, Coroneo M, Haller H, Lindschau C, Quass P, Widerholt M (1989) Continuous membrane voltage recordings in Al0 vascular smooth muscle cells: effect of AVP. Am J Physiol 257:C323-C332.

Lebrun CJ, Gruber MG, Meister M, Unger T (1990) Central vasopressin pretreatment sensitizes phosphoinositol hydrolysis in the rat septum. Brain Res 531:167-172.

I eong DA (1988) A complex mechanism of facilitation in pituitary ACTH cells: recent single-cell studies. J Exp Biol 139:151-168.

Liou SY, Albers HE (1989) Single unit response of suprachiasmatic neurons to arginine vasopressin (AVP) is mediated by a $V_{1}$-like receptor in the hamster. Brain Res 477:336-343.

Llinas RR (1988) The intrinsic electrophysiological properties of mammalian neurons: insights into central nervous system function. Science 242:1654-1664.

Lowbridge J, Manning M, Haldar J, Sawyer WH (1977) Synthesis and some pharmacological properties of [4-threonine, 7-glycine] oxytocin, [1-(L-2-hydroxy-3-mercaptopropanoic acid),4-threonine,7-glycine]oxytocin (hydroxy[ $\left.\mathrm{Thr}^{4}, \mathrm{Gly}^{7}\right]$ oxytocin), and [7-glycine]oxytocin, peptides with high oxytocic-antidiuretic selectivity. J Med Chem 20: $120-123$.

Ma RC, Dun NJ (1985) Vasopressin depolarizes lateral horn cells of the neonatal rat spinal cord in vitro. Brain Res 348:36-43.

Manning M, Bankowski K, Sawyer WH (1987) Selective agonists and antagonists of vasopressin. In: Vasopressin, principles and properties (Gash DM, Boer GJ, eds), pp 335-368. New York: Plenum.

Martin SC, Yule DI, Dunne MJ, Gallacher DV, Petersen OH (1989) Vasopressin directly closes ATP-sensitive potassium channels evoking membrane depolarization and an increase in the free intracellular $\mathrm{Ca}^{2+}$ concentration in insulin-secreting cells. EMBO J 8:3595-3599.

Mollard P, Vacher P, Rogawski MA, Dufy B (1988) Vasopressin enhances a calcium current in human ACTH-secreting pituitary adenoma cells. FASEB J 2:2907-2912.

Moratalla R, Vallejo M, Lightman SL (1988) Vasopressin stimulates inositol phospholipid metabolism in rat medulla oblongata in vivo. Brain Res 450:398-402.

Mühlethaler M, Dreifuss JJ, Gähwiler BH (1982) Vasopressin excites hippocampal neurones. Nature 296:749-751.

Paponnc PA (1980) Voltage-clamp experiments in normal and denervated mammalian skeletal muscle. J Physiol (Lond) 306:377-410.

Peters S, Kreulen DL (1985) Vasopressin-mediated slow EPSP in a mammalian sympathetic ganglion. Brain Res 339:126-129.

Poulin P, Lederis K, Pittman QJ (1988) Subcellular localization and characterization of vasopressin binding sites in the ventral septal area, lateral septum, and hippocampus of the rat brain. $J$ Neurochem 50: 889-898.
Pradelles P, Morgat JL, Fromageot P, Camier M, Bonne D, Cohen P, Bockaert J, Jard S (1972) Tritium labeling of (8-lysine)-vasopressin and its purification by affinity chromatography on sepharose-bound neurophysin. FEBS Lett 26:189-192.

Raggenbass M, Tribollct E, Drcifuss JJ (1987) Electrophysiological and autoradiographical evidence of $V_{1}$ vasopressin receptors in the lateral septum of the rat brain. Proc Natl Acad Sci USA 84:77787782.

Raggenbass M, Dubois-Dauphin M, Tribollet E, Dreifuss JJ (1988) Direct excitatory action of vasopressin in the lateral septum of the rat brain. Brain Res 459:60-69.

Raggenbass M, Tribollet E, Dubois-Dauphin M, Dreifuss JJ (1989) Vasopressin receptors of the vasopressor $\left(V_{1}\right)$ type in the nucleus of the solitary tract of the rat mediate direct neuronal excitation. J Neurosci 9:3929-3936.

Shewey LM, Dorsa DM (1988) $\mathrm{V}_{\mathrm{1}}$-type vasopressin receptors in rat brain septum: binding characteristics and effects on inositol phospholipid metabolism. J Neurosci 8:1671-1677.

Stephens LR, Logan SD (1986) Argininc-vesoprcssin stimulatcs inositol phospholipid metabolism in rat hippocampus. J Neurochem 46: 649-651.

Sun MK, Guyenet PG (1989) Effects of vasopressin and other neuropeptides on rostral medullary sympathoexcitatory neurons 'in vitro.' Brain Res 492:261-270.

Suzue T, Yanaihara N, Otsuka M (1981) Actions of vasopressin, gastrin releasing peptide and other peptides on neurons of newborn rat spinal cord in vitro. Neurosci Lett 26:137-142.

Tribollet E, Barberis C, Jard S, Dubois-Dauphin M, Dreifuss JJ (1988) Localization and pharmacological characterization of high affinity binding sites for vasopressin and oxytocin in the rat brain by light microscopic autoradiography. Brain Res 422:105-118.

Tribollet E, Goumaz M, Raggenbass M, Dubois-Dauphin M, Dreifuss JJ (1991) Dev Brain Res 58:13-24.

Van Leeuwen FW (1987) Vasopressin receptors in the brain and pituitary. In: Vasopressin, principles and properties (Gash DM, Boer GJ, eds), pp 477-496. New York: Plenum.

Van Renterghem C, Romey G, Lazdunski M (1988) Vasopressin modulates the spontaneous electrical activity in aortic cells (line A7r5) by acting on three different types of ionic channels. Proc Natl Acad Sci USA 85:9365-9369.

Wang YY, Aghajanian GK (1987) Excitation of locus coeruleus neurons by an adenosine $3^{\prime}, 5^{\prime}$-cyclic monophosphate-activated inward current: extracellular and intracellular studies in rat brain slices. Synapse $1: 481-487$.

Wang YY, Aghajanian GK (1990) Excitation of locus coeruleus neurons by vasoactive intestinal peptide: role of CAMP and protein kinase A. J Neurosci 10:3335-3343.

Weiss RE, Horn R (1986) Functional differences between two classes of sodium channels in developing rat skeletal muscle. Science 233: 36I-364. 